\title{
Analisis Pengaruh Persepsi Ibu Terhadap Perilaku Gaya Hidup Bersih dan Sehat Berdasarkan Health Belief Model di Surabaya
}

\section{Analysis on the Effect of Mother's Perception towards the Clean and Healthy Life Behavior Based on the 'Health Belief Model' in Surabaya}

\author{
Minarni Wartiningsih ${ }^{1}$, Danoe Soesanto ${ }^{1}$, Hanna Tabita Hasianna Silitonga ${ }^{1}$, Gianina \\ Angelia Santoso ${ }^{2}$ \\ ${ }^{1}$ Departemen Kesehatan Masyarakat, Fakultas Kedokteran Universitas Ciputra Surabaya \\ ${ }^{2}$ Program Studi Ilmu Kedokteran, Universitas Ciputra Surabaya \\ Corresponding Author: minarni.wartiningsih@ ciputra.ac.id
}

\begin{abstract}
ABSTRAK
Di Surabaya pada tahun 2017, Incidence penyakit diare sebesar 76,602 kasus yang sebelumnya sebanyak 77,617 suspek kasus $(98,69 \%)$. Kota Surabaya memiliki 63 Puskesmas dan dari tahun 2016 hingga tahun 2018, terdapat 12 Puskesmas yang inciden penyakit diare pada balita meningkat. Penelitian ini bertujuan untuk menganalisis pengaruh persepsi ibu yang mengasuh balita terhadap perilaku gaya hidup bersih dan sehat berdasarkan Health Belief Model. Penelitian ini adalah penelitian kuantitatif analitik dengan pendekatan cross-sectional. Terdapat $120 \mathrm{ibu}$ yang mengasuh balitanya dari 12 Puskesmas ikut terlibat dalam penelitian ini. Responden mengisi kuesioner tentang karakteristik, perceived susceptibility, perceived severity, perceived benefit, cues to action and perilaku gaya hidup sehat. Penelitian ini dilakukan pada bulan Mei tahun 2019. Analisis variabel dilakukan dengan uji analisis bivariat dengan regresi binomial. Karakteristik responden yang terdiri dari (usia, tingkat pendidikan dan tingkat sosio ekonomi) pada penelitian ini berpengaruh terhadap perceived susceptibility, perceived severity and perceived benefits. Perceived susceptibility dan perceived severity berpengaruh terhadap perceived barriers, tingkat pendidikan juga berpengaruh terhadap perceived benefits. Cues to action berpengaruh terhadap perceived barriers dan perceived barrier dan perceived benefits berpengaruh terhadap perilaku hidup bersih dan sehat.
\end{abstract}

Kata kunci: Diare, Persepsi, Health Belief Models, PHBS

\section{ABSTRACT}

In Surabaya, the incident of diarrhea reached over 76,602 cases from 77,617 suspect cases $(98,69 \%)$ in 2017. Surabaya owns 63 public health centers (Puskesmas) provided by the government, which 12 of them experiencing an increase in infant diarrhea incident from 2016 until 2018. This research aims to analyze the influence of child-nurturing mother's perceptions towards a clean and healthy life behavior (CHLB) based on the Health Belief Model. This research is a quantitative analytic research with a crosssectional design. There are 120 child-nurturing mothers from 12 public health centers in Surabaya selected as the respondents of this research. The respondents fill out questionnaires about their characteristics, perceived susceptibility, perceived severity, perceived benefit, cues to action, and the clean and healthy life behavior. The research was conducted during May 2019. The variable analysis is accomplished through bivariate analysis test with binomial regression. The characteristics of respondents including age, education level and socio-economic level influence their perceptions toward the perceived susceptibility, severity, and benefits. The perceived susceptibility and severity influence the perceived barriers, meanwhile the education level also influences the perceived benefits. Cues to action influences the perceived barriers, and then the perceived barrier and the perceived benefits influences the clean and healthy life behavior. In conclusion, mother education level is very important in understanding and shaping the perceived severity, perceived benefits, and perceived barriers in diarrheal disease.

Keywords: Diarrhea, Perceptions, Mother, Health Belief Model, CHLB 
Jurnal Manajemen Kesehatan Yayasan RS.Dr.Soetomo Vol.6 No.1 April 2020 :

\section{PENDAHULUAN}

Data dari Riskesdas 2018, menyatakan bahwa prevalensi penyakit diare di Jawa Timur pada 2013 hingga 2018 naik dari 6,6\% menjadi 10,7\%. Penyakit diare masih menjadi penyebab utama kematian bayi dan balita. Pencegahan penyakit diare di Puskesmas dilakukan dengan promosi kesehatan dan pencegahan penyakit. Promosi kesehatan dapat dilakukan melalui pendidikan kesehatan, pada tahun 1950 model psikologis dikembangkan untuk meningkatkan efektivitas program pendidikan kesehatan, pada tahun 1974 yang menunjukkan karakteristik demografis seperti usia, jenis kelamin, etnis, tingkat pendidikan, dan tingkat sosial ekonomi yang diketahui terkait. dengan pola perilaku yang berhubungan dengan kesehatan preventif.1,2. Health Belief Model berfokus pada dua aspek representasi individu dari kesehatan dan perilaku kesehatan: (ancaman yang dirasakan dan evaluasi perilaku), ancaman yang dirasakan dibangun sebagai dua keyakinan utama: kerentanan yang dirasakan terhadap penyakit atau masalah kesehatan dan mengantisipasi keparahan akibat penyakit. Evaluasi perilaku juga terdiri dari dua rangkaian keyakinan yang berbeda: (manfaat atau kemanjuran perilaku kesehatan yang disarankan), dan yang menyangkut hambatan, biaya, dan penetapan perilaku. 760.000 anak di bawah usia lima tahun yang meninggal dalam setahun. Insiden kematian akibat penyakit diare pada anak balita terjadi di negara berkembang dan $75 \%$ kematian terjadi di Asia Tenggara dan Afrika. Selanjutnya kejadian kematian anak-anak di bawah usia lima tahun sebagian besar berasal dari kelompok tingkat sosial ekonomi rendah dan pendidikan tingkat rendah yang tinggal di daerah pedesaan. Jumlah kejadian diare dari 2016 kejadian penyakit diare di fasilitas kesehatan adalah 6.897 .463 dan 2.544.084 kasus ditangani (36,9\%), kejadian diare pada anak di bawah usia lima (balita) di Jawa Timur perkiraan jumlah kasus diare di fasilitas kesehatan adalah 1.048.885 dan 338.806 kasus ditangani (32,3\%), Menurut Profil Kesehatan Kota Surabaya pada tahun 2017, ada 76.602 kasus dari 77.617 kasus dugaan $(98,69 \%)$. Penelitian ini bertujuan untuk mengidentifikasi persepsi ibu balita di kota Surabaya dan menganalisis pengaruh karakteristik perawat ibu balita (umur, tingkat pendidikan 
Danoe Soesanto dkk : Analysis on the Effect of Mother's Perception towards ...

dan tingkat sosial ekonomi), persepsi kerentanan, persepsi keparahan, persepsi manfaat, persepsi hambatan, isyarat untuk bertindak pada perilaku hidup bersih dan ibu pengasuh yang sehat balita. Tujuan dari penelitian ini adalah untuk menganalisis pengaruh karakteristik pengasuh ibu balita, persepsi kerentanan, persepsi tingkat keparahan, persepsi manfaat, persepsi hambatan, isyarat untuk bertindak pada perilaku hidup bersih dan sehat.

\section{METODOLOGI}

Penelitian ini adalah penelitian analitik kuantitatif dengan pendekatan studi observasional. Desain penelitian adalah studi cross-sectional. Populasi adalah ibu yang merawat balita mereka di Surabaya, sebanyak 120 ibu dari 12 perawatan kesehatan primer dipilih. Dua belas perawatan kesehatan primer dipilih karena jumlah kejadian diare dari 2016 hingga 2018 cenderung meningkat. Ukuran Sampel ditentukan oleh rumus Lemeshow. Data dikumpulkan dengan kuesioner dan 10 ibu pada saat yang sama menjawab kuesioner tentang karakteristik, persepsi kerentanan, manfaat yang dirasakan, hambatan yang dirasakan, petunjuk untuk bertindak dan gaya hidup sehat yang dipandu oleh pencacah. Data dianalisis dengan SPSS Statistics untuk analisis bivariat menggunakan regresi binomial. Penelitian ini disetujui oleh Komisi Etika Penelitian Kesehatan Universitas Ciputra.

\section{HASIL PENELITIAN}

Pada penelitian ini karakteristik responden ditunjukan seperti pada tabel 1. dimana sebagian besar usia responden masuk dalam kelompok umur 36 - 40 tahun $(27,50 \%)$. Tingkat pendidikan ibu sebagian besar adalah Sekolah menengah Umum (SMU) (48,30\%). Dan tingkat sosio - ekonomi dari ibu adalah menengah (69\%). 
Tables 1. Karakteristik responden

\begin{tabular}{|c|c|c|c|}
\hline Karakteristik & Kategori & Frekuensi & Persentase \\
\hline \multirow[t]{5}{*}{ Umur Ibu } & $21-25$ Tahun & 18 & 15,00 \\
\hline & $26-30$ Tahun & 25 & 20,80 \\
\hline & $31-35$ Tahun & 26 & 21,70 \\
\hline & $36-40$ Tahun & 33 & 27,50 \\
\hline & $41-45$ Tahun & 18 & 15,00 \\
\hline \multirow[t]{4}{*}{ Tingkat Pendidikan } & SMP & 37 & 30,80 \\
\hline & SMU & 58 & 48,30 \\
\hline & Diploma & 11 & 9,20 \\
\hline & Sarjana & 14 & 11,70 \\
\hline \multirow{3}{*}{$\begin{array}{l}\text { Tingkat } \\
\text { ekonomi }\end{array}$} & Rendah & 35 & 29,20 \\
\hline & Sedang & 81 & 67,50 \\
\hline & Tinggi & 4 & 3,30 \\
\hline Total & & 120 & 100 \\
\hline
\end{tabular}

Persepsi ibu tentang keseriusan, keparahan, hambatan, manfaat dan cues to action tampak pada tabel 2 .

Tables 2. Persepsi Kerentanan, Keparahan, Manfaat, Hambatan, Cues To Actions dan Perilaku Hidup Bersih dan Sehat

\begin{tabular}{llcc}
\hline \multicolumn{1}{c}{ Jenis Persepsi } & \multicolumn{1}{c}{ Hasil Jawaban } & Frekuensi & Persentase \\
\hline Keseriusan & Tidak Serius & 49 & 40,80 \\
& Serius & 71 & 59,20 \\
\hline Keparahan & Setuju dapat menjadi parah & 87 & 72,50 \\
& Tidak setuju dapat menjadi & 33 & 27,50 \\
& parah & & \\
\hline Manfaat & Setuju & 96 & 80,00 \\
& Tidak Setuju & 24 & 20,00 \\
\hline Hambatan & Setuju adanya hambatan & 36 & 30,00 \\
& Tidak setuju ada hambatan & 84 & 70,00 \\
\hline Cues To Action & Setuju akan melakukan & 105 & 87,50 \\
& Tidak setuju akan melakukan & 15 & 12,50 \\
\hline Perilaku Hidup & Mendukung & 105 & 87,50 \\
Bersih dan sehat & Tidak Mendukung & 15 & 12,50 \\
\hline Total & & 120 & 100,00 \\
\hline
\end{tabular}


Danoe Soesanto dkk : Analysis on the Effect of Mother's Perception towards ...

Sebagian besar responden memiliki persepsi kerentanan pada penyakit daire $(59,20 \%)$, sebanyak 72,5 responden setuju dengan pendapat penyakit diare dapat menyebabkan keparahan, Sebagian besar responden setuju bahwa menerapkan perilaku hidup bersih dan sehat dapat bermanfaat dalam mencegah terjadinya penyakit diare (80\%). Sebagian besar responden tidak setuju bahwa ada hambatan yang serius dalam melakukan perilaku hidup bersih dan sehat (70\%). Mayoritas responden $(87,50 \%)$ setuju akan melakukan tindakan seperti apa yang di sampaikan pada informasi penerapan perilaku hidup bersih dan sehat dan pencegahan penyakit diare (cues to action). Perilaku hidup bersih dan sehat responden mayoritas mendukung perilkau hidup bersih dan sehat. Analisis pengaruh karakteristik umur Ibu Pengasuh Balita Terhadap Persepsi Kerentanan (Perceived Susceptibility) tampak pada tabel 3.

Semakin lanjut umur Ibu Pengasuh Balita maka ibu pengasuh balita memiliki persepsi bahwa balita yang diasuh semakin rentan terhadap penyakit diare. Sedangkan semakin muda umur ibu balita masih belum memiliki persepsi kerentanan terhadap penyakit diare. Berdasarkan Analisis bivariat antar variabel menunjukan terdapat pengaruh yang signifikan antara umur ibu pengasuh balita terhadap Persepsi Kerentanan (Perceived Susceptibility) $(\mathrm{P}=0,000)$ dan kekuatan hubungan antara variabel umur ibu balita dengan persepsi kerentanan terdapat kekuatan hubungan sebesar 0,523.

Semakin lanjut umur ibu pengasuh balita maka akan berpersepsi bahwa penyakit daire dapat mengakibatkan dampak yang buruk atau terjadinya keparahan apabila diderita oleh balita, dibandingkan dengan umur ibu yang masih muda. Analisis bivariat menunjukan bahwa terdapat pengaruh yang signifikan antara umur ibu terhadap Persepsi Keparahan (Perceived Severity) $(\mathrm{P}=0,00)$ dengan kekuatan hubungan sebesar 0,375.

Semakin tinggi tingkat pendidikan ibu maka ibu akan mempersepsikan bahwa balita yang diasuhnya lebih rentan terhadap penyakit diare, dibandingkan dengan ibu yang memiliki tingkat pendidikan lebih rendah. Analisis bivariat antar variabel menunjukan bahwa terdapat pengaruh yang signifikan antara tingkat pendidikan ibu pengasuh balita terhadap Persepsi Kerentanan (Perceived 
Susceptibility) $(\mathrm{P}=0,000)$ dan kekuatan hubungan sebesar 0,48. Dan semakin tinggi tingkat pendidikan ibu maka mereka akan mempersepsikan bahwa penyakit diare dapat mengakibatkan sakit yang cukup parah bila diderita oleh balita yang diasuhnya, demikian sebaliknya persepsi ibu dengan tingkat pendidikan yang rendah tidak memahami bahwa penyakit diare dapat mengakibatkan dampak yang cukup serius pada balita yang diasuhnya. Analisis bivariat menunjukan terdapat pengaruh yang signifikan antara tingkat pendidikan ibu terhadap Persepsi Keparahan (Perceived Severity) $(\mathrm{P}=0,041)$ dan kekuatan hubungan hubungan antar variabel sebesar 0,254 .

Semakin rendah tingkat sosio ekonomi ibu balita maka ibu balita memiliki persepsi bahwa balita yang diasuhnya tidak rentan terhadap penyakit diare, dibandingkan dengan ibu balita dengan tingkat sosio-ekonomi yang lain. Analisis bivariat menunjukan bahwa terdapat pengaruh yang signifikan antara tingkat sosio-ekonomi ibu pengasuh balita terhadap Persepsi Kerentanan (Perceived Susceptibility) $(\mathrm{P}=0,000)$ dan kekuatan hubungan sebesar 0,337. Tingkat sosioekonomi ibu yang tinggi memiliki persepsi bahwa penyakit diare dapat menimbulkan dampak yang parah bila diderita oleh balita yang diasuhnya, tingkat sosio-ekonomi ibu yang rendah tentu terkait pada tingkat pemahaman akan pengetahuan tentang penyakit diare. Analisis bivariat menunjukan adanya pengaruh yang signifikan antara tingkat sosio-ekonomi ibu terhadap Persepsi Keparahan (Perceived Severity) $(\mathrm{P}=0,004)$ dengan kekuatan hubungan antar variabel sebesar 0,291.

Semakin lanjut umur ibu maka ibu memiliki persepsi adanya manfaat bila melakukan perilaku hidup bersih dan sehat untuk mencegah terjadinya penyakit diare begitu pula sebaliknya semakin muda usia ibu maka ibu masih belum sepenuhnya memiliki persepsi akan adanya manfaat bila melakukan perilaku hidup bersih dan sehat. Analisis bivariat yang menunjukan tidak adanya pengaruh yang signifikan antara umur ibu terhadap Persepsi Manfaat (Perceived Benefits) $(P=0,807)$. Dengan kekuatan hubungan antar variabel sebesar 0,291.

Semakin tinggi pendidikan ibu pengasuh balita maka akan memiliki persepsi setuju adanya manfaat dalam menerapkan perilaku hidup bersih dan 
Danoe Soesanto dkk : Analysis on the Effect of Mother's Perception towards ...

sehat. Demikian pula sebaliknya, pada ibu dengan tingkat pendidikan yang rendah memiliki persepsi kurang adanya manfaat bila melakukan perilaku hidup bersih dan sehat. Analisis regresi logistik binary dari karakteristik tingkat pendidikan ibu terhadap Persepsi manfaat (Benefits), menunjukan adanya pengaruh yang signifikan $(P=0,002)$. Dengan kekuatan hubungan antar variabel sebesar 0,337. Semakin tinggi tingkat sosio ekonomi ibu maka ibu tidak setuju bila menerapkan perilaku hidup bersih dan sehat akan sangat bermanfaat bagi pencegahaan terjadinya penyakit daire pada balita yang diasuhnya. Analisis bivariat memperlihatkan tidak terdapat hubungan yang signifikan antara tingkat soisoekonomi ibu pengasuh balita dengan Persepsi Manfaat (Perceived Benefits) $(\mathrm{P}=$ 0,128 ) dengan kekuatan hubungan antar variabel sebesar 0,182 .

Semakin lanjut umur ibu maka lebih persepsikan akan semakin banyaknya hambatan dalam menerapkan perilaku hidup bersih dan sehat, demikian pula apabila semakin muda umur ibu maka tidak terlalu mempersoalkan adanya hambatan dalam menerapkan perilaku hidup bersih. Analisis regresi logistik binary antara umur ibu terhadap Persepsi Hambatan (Barrier), menunjukan tidak adanya pengaruh yang signifikan $(\mathrm{P}=0,211)$. Dengan kekuatan hubungan antar variabel sebesar 0,215. Semakin tinggi tingkat pendidikan ibu pengasuh balita maka ibu tidak setuju pada persepsi adanya hambatan-hambatan dalam menerapkan pola hidup bersih dan sehat, hal ini dapat terkait dengan kemudahan dalam pemahaman pengetahuan tentang penyakit diare dan cara-cara menerapkan perilaku hidup bersih dan sehat oleh ibu. Analisis regresi logistik binary antara tingkat pendidikan ibu terhadap Persepsi Hambatan (Perceived Barrier) berpengaruh secara signifikan $(\mathrm{P}=0,031)$ dengan kekuatan hubungan antar variabel sebesar 2,232.

Semakin tinggi tingkat sosio-ekonomi maka ibu memiliki persepsi tidak setuju terdapat hambatan-hambatan dalam menerapkan perilaku hidup bersih dan sehat, Analisis regresi logistik binary menunjukan tidak ada pengaruh yang signifikan terhadap Persepsi Hambatan (Barrier) $(\mathrm{P}=0$ 0,797). Ibu dengan persepsi bahwa balita yang diasuhnya rentan terhadap penyakit diare akan berpersepsi setuju ada hambatan dalam melakukan perilaku hidup bersih dan sehat demikian 
pula bagi ibu yang berpersepsi bahwa balita yang diasuhnya tidak rentan terhadap penyakit diare menyatakan tidak setuju bahwa terdapat halangan dalam menerapkan perilaku hidup bersih dan sehat. Analisis regresi logistik binary dari persepsi kerentanan ibu pengasuh balita terhadap Persepsi Hambatan (Perceived Barrier) menunjukan adanya pengaruh yang signifikan terhadap Persepsi Hambatan (Barrier) $(\mathrm{P}=0,001)$ artinya terdapat hubungan yang signifikan antara persepsi kerentanan ibu terhadap Persepsi Hambatan (Perceived Barrier), dengan kekuatan hubungan antar variabel sebesar 0,124.

Ibu yang menyatakan setuju bahwa balita yang diasuhnya dapat menjadi parah bila menderita diare lebih terkait dengan persepsi setuju masih banyaknya hambatan untuk melakukan pola hidup bersih sehat. Demikian juga sebaliknya pada ibu yang tidak setuju bahwa balita yang diasuhnya dapat menjadi parah bila menderita diare lebih terkait dengan persepsi bahwa tidak setuju masih ada hambatan-hambatan yang dapat menghalangi penerapan perilaku hidup bersih dan sehat. Analisis regresi logistik binary dari persepsi keparahan ibu pengasuh balita terhadap Persepsi Hambatan (Perceived Barrier) menunjukan adanya pengaruh yang signifikan $(\mathrm{P}=0,029)$, dengan kekuatan hubungan antar variabel sebesar 0,354. Ibu yang menyatakan setuju akan bertindak sesuai informasi/pengetahuan yang didapat lebih terkait dengan persepsi yang menyatakan tidak setuju adanya hambatan dalam menerapkan perilaku hidup bersih dan sehat. Demikian juga sebaliknya pada ibu yang menyatakan tidak setuju akan bertindak sesuai informasi/pengetahuan yang didapat lebih terkait dengan persepsi yang menyatakan setuju ada hambatan - hambatan dalam menerapkan perilaku hidup bersih dan sehat. Analisis regresi logistik binary dari Cues To Action ibu dalam bertindak atau mencari pengobatan (Cues To Action) berpengaruh terhadap Persepsi Hambatan (Perceived Barrier) Fisher's Exact Test $=0,002$, dengan kekuatan hubungan antar variabel sebesar 0,043.

Ibu yang setuju dengan adanya manfaat menerapkan perilaku hidup bersih dan sehat lebih terkait dengan perilaku hidup bersih dan sehat yang baik, demikian sebaliknya pada ibu yang tidak setuju dengan manfaat perilaku hidup bersih dan sehat lebih terkait dengan penerapan perilaku hidup bersih dan sehat 
Danoe Soesanto dkk : Analysis on the Effect of Mother's Perception towards ...

yang tidak baik. Analisis regresi logistik binary dari persepsi manfaat ibu pengasuh balita terhadap Perilaku Perilaku Hidup bersih dan Sehat menunjukan adanya pengaruh yang signifikan $(\mathrm{P}==0,017)$ dengan kekuatan hubungan antar variabel sebesar 0,192. Ibu yang berpersepsi setuju terdapat hambatan-hambatan yang sulit saat menerapkan perilaku hidup bersih dan sehat lebih terkait dengan perilaku hidup bersih dan sehat yang tidak baik. Analisis regresi logistik binary dari persepsi hambatan ibu terhadap Perilaku Hidup bersih dan Sehat menunjukan adanya pengaruh yang signifikan $(\mathrm{P}=0,001)$ dengan kekuatan hubungan antar variabel sebesar 0,027 .

\section{PEMBAHASAN}

Pada penelitian ini diketahui bahwa kelompok umur 36 - 40 tahun $(27,50 \%)$ merupakan kelompok usia yang terbanyak membawa balita yang diasuh berobat ke Puskesmas. Pada kelompok umur 36 - 40 tahun telah mencapai perkembangan fisik, kemampuan berfikir, perkembangan psikososial dan emosi serta sosial sehingga rasa tanggung jawab dan cara berfikir telah mengalami perubahan. Perkembangan emosi pada masa awal dewasa muda berhubungan erat dengan kemampuan menjalin hubungan antar individu lain serta ketrampilan dan bersikap dalam mempelajari hal-hal yang baru tentu hal ini juga akan ikut mempengaruhi persepsi kerentanan dan persepsi keseriusan penyakit diare.Hal ini sesuai dengan penelitian sebelumnya bahwa dengan adanya perkembangan dan perubahan cara berfikir dan daya nalar tentu akan mempengaruhi cara mempersepsikan kerentanan dan keseriusan atau dampak derajat keparahan suatu penyakit (Tacca CM, Heine H, 2013; Ostergren E J, et all 2018).

Sebagian besar pendidikan ibu pada penelitian ini adalah Sekolah Menengah Umum, tingkat pendidikan memiliki arti penting dalam memahami dan membentuk persepsi ibu akan pengetahuan tentang manfaat penerapan perilaku hidup bersih dan sehat serta bahaya penyakit diare hal ini sesuai dengan beberapa penelitian sebelumnya diketahui bahwa tingkat pendidikan sangat berhubungan dan memberikan dampak pada persepsi kerentanan, persepsi keparahan dan persepsi manfaat (Khoramabadi et all, 2016; Khalil W M, 2017). 
Tingkat sosio-ekonomi dari ibu pengasuh balita mayoritas adalah tingkat sosio-ekonomi sedang, persepsi ibu dari kelompok tingkat sosio-ekonomi tidak berpengaruh secara signifikan terhadap persepsi kerentanan dan persepsi keparahan ibu pengasuh balita, meskipun tingkat sosio-ekonomi ibu termasuk tingkat sedang atau tinggi belum tentu memiliki tingkat pendidikan dan pengetahuan yang memadai tentang penyakit diare sehingga akan mempengaruhi bagaimana pemahaman ibu terhadap kerentanan dan dampak keparahan yang dapat ditimbulkan oleh penyakit daire. hal ini sejalan dengan beberapa penelitian yang dilakukan sebelumnya (Hosseini $\mathrm{Z}$ et all, 2016).

Umur ibu yang lebih lanjut memberikan berpengaruh terhadap persepsi kerentanan dan persepsi keparahan hal ini dapat dipahami bahwa semakin lanjut umur seseorang maka telah mengalami perkembangan fisik, kemampuan berfikir, perkembangan psikososial dan emosi serta social.

Pada penelitian sebelumnya diketahui bahwa tingkat pendidikan sangat penting artinya bila disertai dengan pengetahuan yang baik tentang penyakit tertentu (Francesco Napolitano F, 2019; Reisi M, 2015), Tingkat pendidikan ibu pada penelitian ini berpengaruh terhadap persepsi hambatan. Dengan bekal tingkat pendidikan yang memadai tentu akan mempermudah dalam memahami dan mengerti tentang bahaya penyakit diare serta pencegahannya dengan menerapkan perilaku hidup bersih dan sehat.

Umur dan tingkat sosio-ekonomi ibu pada penelitian ini tidak berpengaruh secara signifikan terhadap persepsi manfaat. Hal ini bertolak belakang dengan penelitian sebelumnya dimana umur dan tingkat sosio-ekonomi berpengaruh pada persepsi manfaat (Mohsen M M, 2016), pada penelitian tersebut dikatakan bahwah faktor pengetahuan dan tingkat pendidikanlah yang lebih banyak berperan pada persepsi manfaat yang didapat bila melakukan tindakan pencegahan. Meskipun umur seseorang telah memiliki daya nalar dan kemampuan konitif tinggi serta tingkat sosio-ekonomi yang baik namun bila tanpa di sertai pengetahuan akan bahaya penyakit tertentu maka tetap saja tidak akan memberikan pengaruh pada pembentukan persepsi manfaat. 
Danoe Soesanto dkk : Analysis on the Effect of Mother's Perception towards ...

Umur ibu tidak berpengaruh terhadap persepsi hambatan, dengan bertambahnya umur ibu yang telah banyak memiliki pengalaman hidup namun tanpa bekal pengetahuan akan bahaya penyakit diare tentu tidak akan terfikirkan adanya hambatan-hambatan dalam melakukan pencegahan terhadap penyakit diare. Tingkat sosio-ekonomi ibu tidak mempengaruhi persepsi hambatan. Hambatan dalam melakukan tindakan pencegahan penyakit diare bisa jadi dipersepsikan hanya hambatan atau halangan yang mudah atau tidak berarti bila pengetahuan tentang penyakit diare tidak memadai. Adanya kemudahan untuk menyediakan sarana dan prasarana serta kemudahan mendapat informasi di media sosial ataupun media elektronik lainnya merupakan salah satu faktor bagi ibu dalam meniadakan hambatan-hambatan yang ada. Hal ini sejalan dengan penelitian sebelumnya tentang pencegahan penyakit asthma (Cut Husna, 2012).

Ibu yang memiliki persepsi bahwa balitanya rentan terhadap penyakit diare menyatakan setuju bahwa ada hambatan dalam melakukan perilaku hidup bersih dan sehat, hal ini dikarenakan pemahaman terhadap penyakit diare ibu akan bahaya penyakit daire telah dipahami dengan baik namun masih merasa ada faktor lain selain informasi dan pengetahuan tentang penyakit diare yang dapat menjadi faktor penghambat dalam menerapkan perilaku hidup bersih dan sehat. Jadi perlu ada penelitian lebih lanjut tentang faktor-faktor lain yang dapat menjadi penghambat dalam menerapkan perilaku hidup bersih dan sehat. Ibu yang kurang memahami bahaya penyakit diare beserta pencegahannya serta belum membudayanya perilaku hidup bersih dan sehat, memandang bahwa hambatanhambatan dalam melakukan pencegahan penyakit diare tidak sulit untuk dilakukan. Hambatan-hambatan yang ada lebih banyak terkait dengan kemauan untuk melakukan pencegahan jadi bukan dari sarana maupun prasarana, hal ini sejalan dengan penelitian dari ( $\underline{\text { Shao }}$ C, 2018).

Ibu yang menyatakan setuju bahwa balita yang diasuhnya dapat menjadi parah bila menderita diare lebih terkait dengan persepsi setuju masih banyak hambatan untuk melakukan perilaku hidup bersih sehat. Hal ini dapat dimengerti bahwa ibu telah memahami dengan baik hal - hal yang dapat menjadi hambatan dalam menerapkan perilaku hidup bersih dan sehat sehingga berpersepsi bahwa 
masih banyak hambatan - hambatan dalam menerapkan perilaku hidup bersih dan sehat. Manfaat PHBS ibu yang setuju dengan adanya manfaat menerapkan perilaku hidup bersih dan sehat lebih terkait dengan perilaku hidup bersih dan sehat yang baik, demikian sebaliknya pada ibu yang tidak setuju dengan manfaat perilaku hidup bersih dan sehat lebih terkait dengan penerapan perilaku hidup bersih dan sehat yang tidak baik. Hal ini dapat dimengerti bahwa pemahaman ibu tentang manfaat yang besar dengan mencegah penyakit diare tentu akan memotivasi untuk diterapkan.

Cues to Action pada penelitian ini berpengaruh terhadap persepsi hambatan atau barrier, perilaku Cues To Action tentu akan mengurangi atau memperkecil persepsi hambatan dari ibu. Cues to action terdorong oleh adanya motivasi yang kuat untuk melakukan pencegahan atau mencari petolongan. Informasi yang di dapat baik dari media masa maupun sumber lainnya harus dapat memotivasi ibu dalam melakukan pencegahan atau mencari pertolongan terhadap balita yang terjangkit daire. Hal ini sesuai dengan penelitian yang di lakukan oleh (Puspita et all, 2017). Penelitian sebelumnnya mengungkapkan bahwa Cues to Action sangat di pengaruhi oleh tingkat pengetahuan dan dukungan sosial yang ada dari ibu pengasuh balita sehingga dapat menimbulkan kemauan untuk melakukan perilaku baik pencegahan, mencari pertolongan serta pengobatan (Huang H T et all, 2016).

Persepsi manfaat pada penelitian ini berpengaruh terhadap perilaku hidup bersih dan sehat, hal ini sejalan dengan beberapa penelitian sebelumnya, apabila ibu merasakan manfaat melakukan pencegahan penyakit diare sangat besar maka ibu akan menerapkan perilaku hidup bersih dan sehat. Manfaat menerapkan perilaku hidup bersih dan sehat perlu diketahui dan dirasakan oleh ibu agar mau membudayakan perilaku hidup bersih dan sehat sehingga balita yang diasuhnya akan terhindar dari penyakit diare (Mohebi $S$ et all, 2013). Persepsi hambatan pada penelitian ini berpengaruh terhadap perilaku hidup bersih dan sehat dalam mencegah penyakit diare, bila ibu mempersepsikan hambatan yang ada mudah diatasi maka ibu akan termotivasi menerapkan perilaku hidup bersih dan sehat. 
Danoe Soesanto dkk : Analysis on the Effect of Mother's Perception towards ...

Hasil penelitian ini sama dengan hasil penelitian sebelumnya yang dilakukan oleh Khani dkk (Khani J A et all, 2018).

\section{SIMPULAN}

Tingkat pendidikan ibu sangat penting artinya dalam memahami tentang pentingnya menerapkan perilaku hidup bersih dan sehat serta bahaya penyakit diare, tingkat pengetahuan ibu tentang perilaku hidup bersih dan sehat dapat ditingkatkan dengan memberikan informasi baik dengan penyuluhan atau demontrasi tentang perilaku perilaku hidup bersih dan sehat. Persepsi kerentanan, persepsi keparahan, persepsi hambatan dan persepsi manfaat juga dipengaruhi oleh tingkat pendidikan ibu. Persepsi manfaat yang dirasakan ibu diharapkan akan menurunkan persepsi hambatan dalam melakukan perilaku hidup bersih dan sehat.

\section{UCAPAN TERIMA KASIH}

Ucapan terima kasih penulis ucapkan kepada semua pihak yang membantu terlaksananya penelitian ini terutama kepada Departemen Kesehatan Masyarakat, Fakultas Kedokteran Universitas Ciputra Surabaya dan Seluruh pihak yang telah mendukung dan membantu penelitian ini hingga selesai.

\section{DAFTAR PUSTAKA}

Ambike D, Haribhakta S, BhavariV, Raje S and Varghese M, 2018, Perception of parents on childhood diarrhoea and its co-relation with their knowledge score, International Journal of Contemporary Pediatrics, Vol.5, No.3, pp:912-916.

Baharzadeh K, Marashi T, Saki A, Javid Z A, Araban M, 2017, Using of Health Belief Model to Promote Preventive Behaviors Against Iron Deficiency Anemia Among Pregnant Women, Journal of Research \& Health, Vol.7, No.2,pp: 754- 762 .

Benova L, Campbell OMR and Ploubidis GB, 2014, Socio-Economic Gradients in Maternal and Child health Seeking Behaviours in Egypt: Systematic Literature Review and Evidence Synthesis, PloS ONE, Vol.9, No. 3, e93032.

BPS Kota Surabaya

https://surabayakota.bps.go.id/dynamictable/2018/04/18/22/proyeksipenduduk-kota-surabaya-menurut-jenis-kelamin-dan-kelompok-umurtahun-2018

Chen D Gin, Huang N Chien,Yang Y Sun and Lew-Ting C Yin, 2014, Patient Perception of Understanding Health Education and Instructions Has Moderating Effect on Glycemic Control, BMC Public Health, Vol.14, p.683 
Conner, M. and Norman, P. (2005) Predicting Health Behaviour: Research and Practice with Social Cognition Models. 2nd Edition, Open University Press, Maidenhead.

Cut Husna, 2012, Upaya Pencegahan Kekambuhan Asma Bronchial Ditinjau Dari Teori Health Belief Model Di Rsudza Banda Aceh, Idea Nursing Journal, Vol. III No. 3.

Galen E. Cole G E, Holtgrave D R, Rios N M, Internal And External Factors That Encourage Or Discourage Health-Relevant Behaviors, [Cited: 2019 July 28$].$ https://www.orau.gov/cdcynergy/soc2web/Content/activeinformation/resour ces/Health_Behavior_Factors.pdf

Gibsons J, John M, Ivanicevich dan Donelly H, 2009, Organisasi dan Manajemen, Perilaku, Struktur dan Proses, Erlangga, Jakarta.

Haefner, D.P. and Kirscht, J.P. (1970) Motivational and behavioural effects of modifying health beliefs, Public Health Reports, 85, 478-84.

Hanson J A, Benedict J A,2002, Use of the Health Belief Model to Examine Older Adults' Food-Handling Behaviors, Journals of Nutrition Education and Behaviour, Vol.34(1), Pp S25-S30

Hellriegel D, Jackson S dan Slocum J, 2005, Management, $10^{\text {th }}$ edition, SouthWestern Cengage Learning, USA.

Hosseini Z, Karimi Z, Mohebi S, Sharifirad G R, Rahbar A, Gharlipour Z, 2016, Nutritional Preventive Behavior of Osteoporosis in Female Students: Applying Health Belief Model (HBM), International Journal Pediatric, Vol. 5(1), pp.4137-44.

Huang H T,Kuo Y M , Wang S R, Wang C F and Tsai C H, 2016, Structural Factors Affecting Health Examination Behavioral Intention, International Journals Environ. Res. Public Health, Vol.13, pp.395.

Hurlock, B Elizabeth, 1981, Developmental Psycology: A Life-span Approach, New Delhi: Tata Mc Graw Hill, 5 Ed,

Janz \& Beckers, 1984, The Health Belief Model: A Decade Later, Health Education Quarterly, Sage Journals, vol11(1), pp1-47.

Khani J A, Kashfi S H, Bahmandost M, Harsini P A, 2018, Promoting Preventive Behaviors of Nosocomial Infections in Nurses: The Effect of an Educational program based on Health Belief Model, Invest Educ Enferm,Vol. 36,No1.pp.09.

Khalil W M, 2017, Effect Of Health Education Intervention On Improving Compliance To Treatment Among Hypertensive Patients: Application Of Health Belief Model, Journal of Hypertension Vol 35, e-Supplement 2, OP.2B.05, e 16.

Khoramabadi M, Dolatian M, Hajian S, Zamanian M, Taheripanah M, Sheikhan Z, Mahmoodi Z and Moghadam A S. 2016, Effects of Education Based on Health Belief Model on Dietary Behaviors of Iranian Pregnant Women, Global Journal of Health Science, Vol. 8(2): 230-239.

Kemenkes RI, Profl Kesehatan RI Tahun 2016, Jakarta, Kementrian Kesehatan RI, 2016. 
Kundu TR, Prateepchaikul L and Sen-Ngam K, 2010, Relationship between Maternal Perceptions and Preventive Behaviors Regarding Acute Diarrhea of Children in Bangladesh, The $2^{\text {nd }}$ International conference on Humanities and Social Sciences, Faculty of Liberal Arts, Prince of Songkla University.

Mohebi S, Azadbakht L, Feizi A, Sharifirad G, Kargar M, 2013, Structural Role of Perceived Benefits and Barriers to Self-Care in Patients With Diabetes, Journals Edu Health Promotion, Vol.2, pp:37

Mohsen M M, El-Abbassy A. A, Khalifa M A, 2016, Effect of application of a Health Belief Model on changing mothers' beliefs regarding birth spacing in rural areas, Clinical Nursing Studies Journal,Vol. 4, No.3,pp.54-66.

Napolitano F, Ali AA, Vastola A and Angelil F I, 2019, Rotavirus Infection and Vaccination: Knowledge, Beliefs, and Behaviors among Parents in Italy, International Journal Environment. Res, Vol.16, p.1807.

Ostergren E J, Heeringa S G, Mendes F C, Connell C M and Roberts J Scott, 2018, The Influence of Psychosocial and Cognitive Factors on Perceived Threat of Alzheimer's Disease, PMC, Am J Alzheimers Dis Other Demen, Vol.32(5): pp.289-299.

Puspita R C , Didik Tamtomo D, Indarto D, Health Belief Model for the Analysis of Factors Affecting Hypertension Preventive Behavior among Adolescents in Surakarta, Journal of Health Promotion and Behavior, Vol.2(2): 183-196

Reisi M, Alidosti M,Tavassoli E, Kargar M, Dehkordi Z R and Ashrafi H A, 2015, Investigating of Mothers' Behavior Based on the Health Belief Model about Using Iron Supplementation in 6 to 24- Month Old Children in Shahrekord City, Iran, British Journal of Medicine \& Medical Research, Vol.5(9): 1140-1146.

Riskesdas 2013, from http://kesga.kemkes.go.id/images/pedoman/Data\%20Riskesdas\%202013.pdf

Robbins, S.P. 2001 Organizational Behavior. 9th Edition, Prentice-Hall, Inc., New York.

Rosenstock, I M, 1966, Why People Use Health Servces, The Milbank memorial Fund Quarterly, Vol.44,pp.94-127.

Rosenstock I M, Strecher V J \& Becker M H, 1988, Social Learning Theory and The Health Belief Model, Health Educaion, Quarterly, Vol.15, pp.175-183

Shao C'Wang J, Liu J, Tian F, Lie H, 2018, Effect of a Health Belief Model-based education program on patients' belief, physical activity, and serum uric acid: a randomized controlled trial, Patient Prefer Adherence. Vol.12:pp.1239-1245.

Sobur A, 2011, Psikologi Umum, CV. Pustaka Setia, Bandung

Tacca CM, Heine H, 2013, Linking Perception And Cognition, Frontiers in Psychology, Vol. 4, pp.144.

Undang-undang Republik Indonesia Nomor 36 Tahun 2009 Tentang Kesehatan, Jakarta, Depkes RI, 2009.

World health Orgaization, 1947, Health Definition [cited 201902 January].

Available from: https://www.who.int/about/mission/en/

World Health Organization, Diarrhoe disease, 2013, [cited 201902 January] Available from: https://www.who.int/topics/diarrhoea/en/ 
Jurnal Manajemen Kesehatan Yayasan RS.Dr.Soetomo Vol.6 No.1 April 2020 :

Zimmerman E and Woolf $\mathrm{H}$ Steven, 2014, Understanding the Relationship sBetween Education and Health, Institute of Medicine, the National Academy of Sciences, [http://nam.edu/wp-content/upl

\begin{tabular}{|l|l|}
\hline Submission & 23 Februari 2020 \\
\hline Review & 10 Maret 2020 \\
\hline Accept & 07 April 2020 \\
\hline Publish & 23 April 2020 \\
\hline DOI & $10.29241 /$ jmk.v\%vi\%i.310 \\
\hline Sinta Level & 4 (Empat) \\
\hline
\end{tabular}

